\title{
Soundscape in North-Eastern Part of Iasi City (Sararie - Ticau District)
}

\author{
Ana Maria OIȘTE ${ }^{1 *}$, Florin Constantin MIHAI ${ }^{2}$, Dan Adrian CHELARU². \\ ${ }^{1}$ Department of Hydrotechnics , Geodesy and Environmental Engineering. University of Iasi, Romania. \\ ${ }^{2}$ Faculty of Geography and Geology University "Alexandru Ioan Cuza" - (University) Iasi (Romania). \\ * corresponding author: anamaria.oiste@yahoo.com
}

Bulletin USAMV series Agriculture 72(1)/2015

Print ISSN 1843-5246; Electronic ISSN 1843-5386

DOI 10.15835/buasvmcn-agr: 11190

\begin{abstract}
This paper presents a complex study of noise levels from road traffic source and the variation during the seasons in an old residential area located in the north-eastern part of Iasi city, an important educational and cultural centre of the country.

The study reveal the correlation between noise levels and social activities developed in the area: low number of inhabitants because of the holidays time in August and the resumption of the educational activity in autumn, including school start in September and of the university activity in October.

After direct observations, the measurements were made with digital sound -level meter Quest Technologies, 1400 model in five hour intervals 7:00 - 8:00; 10:00 - 11:00; 13:30 - 14:30; 18:00 - 19:00; 19:00 - 20:00. The monitoring of Equivalent Continuous Noise Level (Leq) were made in 30 points located along the different type of roads in the second part of August - October 2009, with different admissible levels, showing the exceeding of the limit in 5 points in September and 8 points in October.

It can be observed an important difference during the week in the monitoring period, between Monday to Friday and the week-end with lower values 59.64 - $6.5 \mathrm{~dB}(\mathrm{~A})$ in August, 61.98 - $5.14 \mathrm{~dB}(\mathrm{~A})$ in September, 63.9 - 5.3 $\mathrm{dB}(\mathrm{A})$ in October and among the four street categories with major differences between first category: $66.89 \mathrm{~dB}(\mathrm{~A})$ and fourth category $47.69 \mathrm{~dB}(\mathrm{~A})$, so that urban noise can be stratified according to a prior classification of a town's streets due to their use and functional characteristics.

Sound levels monitoring and statistical data processing (Pearson correlation coefficient, Tukey range test) sustain the fact that road traffic is main source of noise in the area, differentiated in correlation with street category, a decrease in noise with increasing street category, with insignificant differences between first and second street category thank to the best management and traffic control.
\end{abstract}

Keywords: admissible levels; Iasi city: noise; residential area; seasonal variation;

\section{INTRODUCTION}

Noise pollution is by now worldwide recognized as a major problem for the quality of life in urban areas. Traffic noise is often perceived as one of the biggest environmental problem. Many studies illustrate a link between exposure to noise and negative effects on public health. Noise may severely impair quality of life (disrupt sleep, interfere with speech intelligibility, etc), or possibly giving rise to both social and psychological problems. Such type of disturbances can also create risk of cardiovascular conditions
(Babisch, 2005; Kihlman, 2006, Klaeboe et al., 2005, Ohrstrom and Skanberg, 2004).

By adding together these three major sources of attenuation - geometric spreading, barriers and ground effects - one obtains the total attenuation. The sound level at a certain location is arrived at by adding the sound pressure level of all sound sources to their directivity indexes and subtracting from this sum the total attenuation (Surya et al., 2010).

In spite of lack of experience in this field, as a new-comer in EU, Romania has to comply the 
European Noise Directive (Directive 2002/49/ EC of the European Parliament and of the Council of 25 June 2002 relating to the assessment and management of environmental noise - Declaration by the Commission in the Conciliation Committee on the Directive relating to the assessment and management of environmental noise) and is compulsory to produce the first noise assessment maps.

The evaluation and the management of the noise represent one of the challenge for Romania, that impose for each large city the existence of noise map computed separately for each noise source: the road traffic, the railway traffic, aircrafts and the industrial activities and one that summarize all the results, according to the GD no 674/2007.

Noise levels inside cities represent one of major problem of quality life of the inhabitants, especially in residential districts as Sararie - Ticau districts located in north-eastern part of Iasi city, were the amount of the exposed population is important.

There is a large number of researches which analyze noise levels that used a variety of different approaches in the domain:

- methods and techniques for noise evaluation in urban areas (Deliu, 2008), sources and pollution levels (Can, 2007), legislation (Condorachi, 2006, Popescu, 2007).

- exposure and health, social and economic harmful effects (Bluhm, 2004, Al-Mutairi, 2011).

- control and management urban noise (Condorachi, 2002, Herişanu, 2006).

- other cities of Romania noise studies Cluj Napoca (Mihăiescu, 2007, Popescu, 2011), Braşov (Țârulescu, 2007, Deliu, 2008), Drobeta Turnu Severin (Demian, 2009), Iasi (Condorachi, 2009).

Given its position and the role it plays as part of the urban area system of the country, Iasi city is an urban centre with over 300,000 inhabitants, with an important spatial and functional dynamics, where the noise levels monitoring and management represent a complex task due to the variation along the different street category and during the seasons succession, especially in residential districts where the high noise levels exposure can cause health harmful effects and reducing quality life standard.

The study has a major objective: presenting the sound variation during the season in a residential district of Iasi city, revealing the differences, so that a diminution plan could be implemented. The analisys was realized in three different steps, the most difficult one was the study of the legislation and establish the spatial distribution of the measurement points and street category (four type) and the temporal interval of the research, because of the lack of information. The second challenge was the monitoring activity and the last one to create and organize the database with surveyed values.

\section{MATERIALS AND METHODS}

\section{Street category}

The Romanian standard STAS 10009-88 "Urban acoustics" was the main legislative document that established the admissible levels of the noise in urban area, differentiated on functional zones and technical category of streets (on the base of the technical settlements).

Category I - main, six - lane streets, including tram lanes whose function is to form a connection with national roads, with admissible levels situated between 75 - $85 \mathrm{~dB}(\mathrm{~A})$. It include four measurements points, located onIndependence Blvd.

Category II - linking, four - lane streets, including tram lanes that support major circulation flux between functional and residential area of the city, with admissible level $70 \mathrm{~dB}(\mathrm{~A})$, including five points on C. A. Rosseti Blvd.

Category III - collecting, two - lane street, that collect car flux from different functional areas and allow communication with the two previously defined types of street, with admissible level 65 $\mathrm{dB}(\mathrm{A})$, with 13 points located on N. Balcescu Str., Albinet Str. etc.

Category IV - local serving streets with low traffic ensuring the access in residential area with admissible level $60 \mathrm{~dB}(\mathrm{~A})$ and 8 points on S. Barnutiu Str., Caprelor Str., Basota Str.etc.

That categorization ensure a differentiated analysis of obtained data according to the law and to the admissible levels for each one and all district street were assigned to one of the above categories. Besides the technical categories a street fits, it is also important the type of surface cover: asphalted $-58 \%$, concreted $-26 \%$, graveled - $9 \%$ and unpaved $7 \%$.

\section{Studied area}




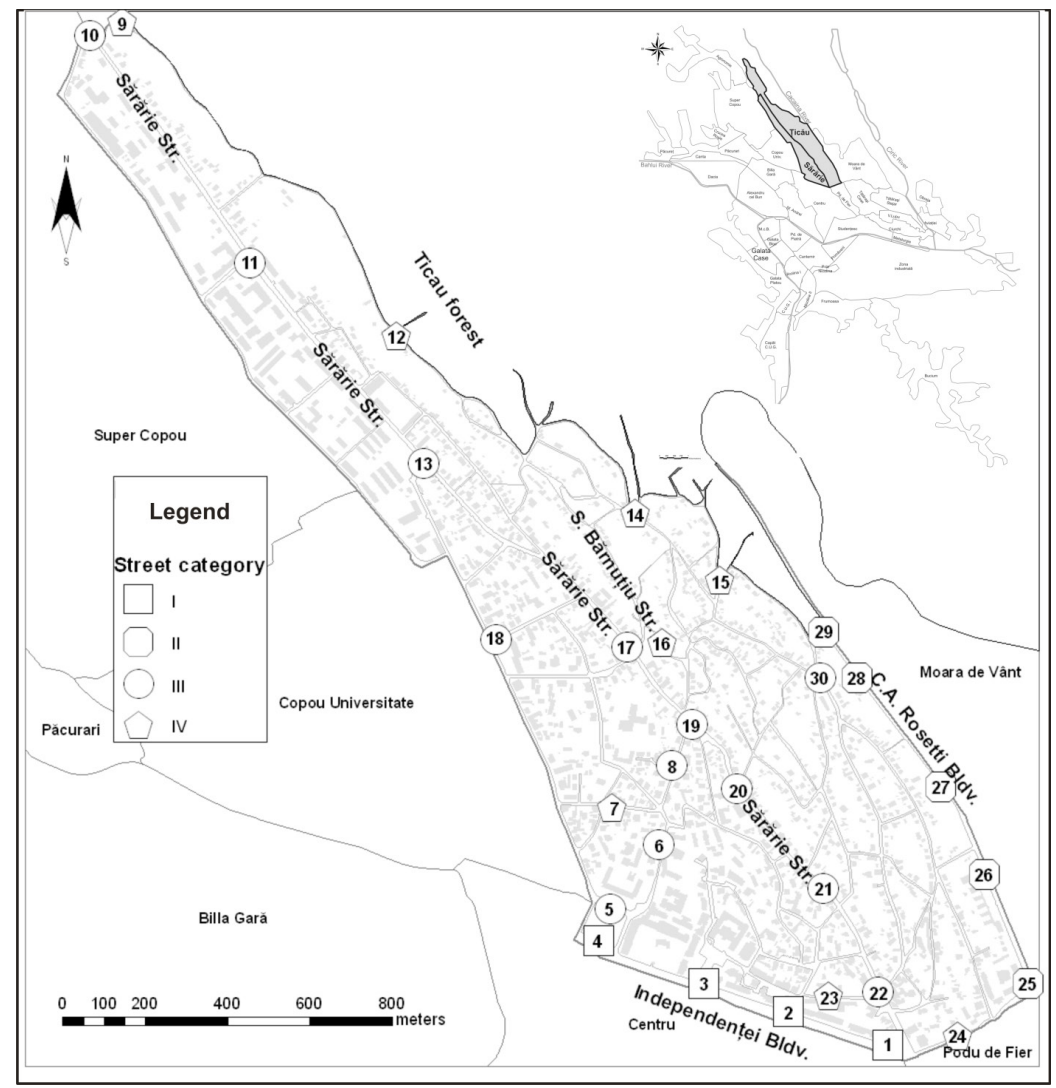

Fig. 1. Study area location and measurements point location

Sararie Ticau districts are located in the north-eastern part of Iasi city, being part of an old residential area of the city, with 4787 inhabitants and 1711 buildings. There weren't located industrial units or public transport lane, exception is Independence Blvd. where the inhabitants are using personal cars for transport

Another important aspect of this residential is the buildings typology, especially the number of levels, façade type and the type of joinery, with implications in noise levels perceived by the inhabitants inside the house.

The number of levels predominating the buildings with only one and two levels $86 \%$, with only $1 \%$ buildings with more than four level located along Independence Blvd. Concerning the facade type, buildings divide in those with polystyrene insulation with a $28 \%$ prevalence and the rest of $72 \%$ are buildings without polystyrene insulation. Referring to the classification of the buildings concerning their joinery, insulated openings with $22 \%$ and without insulation $33 \%$, the rest having both type of joinery.
Studied area is situated in proximity of the most important educational area of the city: Copou University district (over 400 meters) and Ticau forest, one of the green and recreational area of the city that influenced noise levels seasonal variation.

\section{Monitoring points selection}

Point selection was settled after establishing the limits of studied area, street categorization and the length of each category. After that field observation assured the recognition of the street and the cross roads, known as noisiest points, followed by the elimination of points with the same noise levels and the location of the final monitoring points avoiding an arbitrary selection that frequently are the noisiest ones. Figure 1 presents the number, the location and the type of points, according to each street type and it length.

Moreover, an other criteria of selection was the spatial distribution of educational (13 units including primary school and colleges), sanitary ( 10 units wherefrom 3 are hospitals whit regional importance - Saint Spiridon Hospital, Pneumology Hospital and Parascheva Saint Hospital) and 
economical units (83 units with commercial profile) and the correlation of it position and noise levels registered, sustaining the fact that the road traffic is the main noise source in the studied area. There also revealed differences between the districts, in Ticau district are located only economical units, without parking places.

\section{Noise monitoring}

The noise monitoring was conducted in five hour intervals, 7:00 - 8:00 am; 10:00 - 11:00 am; 13:30 - 14:30 pm; 18:00 - 19:00 pm; 19:00 - 20:00 $\mathrm{pm}$, for 10 minutes measurements, being made in the period from 7:00 am to 8:00 pm. The choice of these intervals was made after field observation of population and car fluxes during the week, in accordance with working hours succession during the day. The measurements were made with the use of digital sound - level meter Quest Technologies, 1400 model, with tripod located at $1 \mathrm{~m}$ from the curb.

Seasonal variation of noise levels was highlighted through noise monitoring in the last two weeks of each month from August to October 2009. This period was chosen because it reveals the correlation between noise levels and social activities developed in the area: low number of inhabitants because of the holidays time in August and the resumption of the educational activity in autumn, including school start in September and of the university activity in October.

\section{Statistical methods}

The most commonly variable chosen in noise studies is Equivalent Continuous Noise Level (Leq), that was used also in Noise Map of Iasi city (http://www.primaria-iasi.ro/ content.aspx?item $=$ 1856\&lang=R0), allowing comparison with official data. To represent the obtained values was used box and whisker plot, Pearson correlation coefficient and Tukey test for establish the differences between pairs of nonadjacent categories (Jaba, et al, 2012) were always significant, indicating the stratification of noise in street categories.

\section{RESULTS AND DISCUSSION}

\section{Category analysis}

After 420 measurements for each month in 30 points distributed overall research area the mean of obtained values for Leq were summarized as scatter chart in fig. 2., that show the differences between each month and technical street category, with values over 43.21 and $65.13 \mathrm{~dB}$ in August and 47.25 and $74.5 \mathrm{~dB}$ in October, with intermediate values in September. The technical street typology involve some restriction caused by the width and by the number of lane, observing that two-lane Sararie street (III category) record higher values.

To check if the values fit over admissible values the table 1 , with mean values was added highlighting the data that exceed the limit, for each street category, showing the problem of Sararie street were the mean values exceed the limit with more than $5 \mathrm{~dB}$, point no 22 in October, exposing the population at high noise levels, problem reported also by the authorities that computed city noise map and its report for entire area of the Iasi city.

Another street included in second category, were is registered an exceed with is C. A. Rosseti Blvd, point 25, located near an important crossroad.

\section{Variation during the week}

The results for the variation during the week, compared with weekend time in the three months are summarized in the box-and-whisker plots in figure 4. In these plots, the edges of a box are the quartiles, the horizontal center line is the median, and the horizontal thin black lines are the maximum and minimum values.

They reveal main differences between street category and week period when monitoring was made, with lower values in week-end by the same pattern, for all three month, with lower values on summer and higher in autumn, when the admissible are exceeded for first and second street category during the week in September

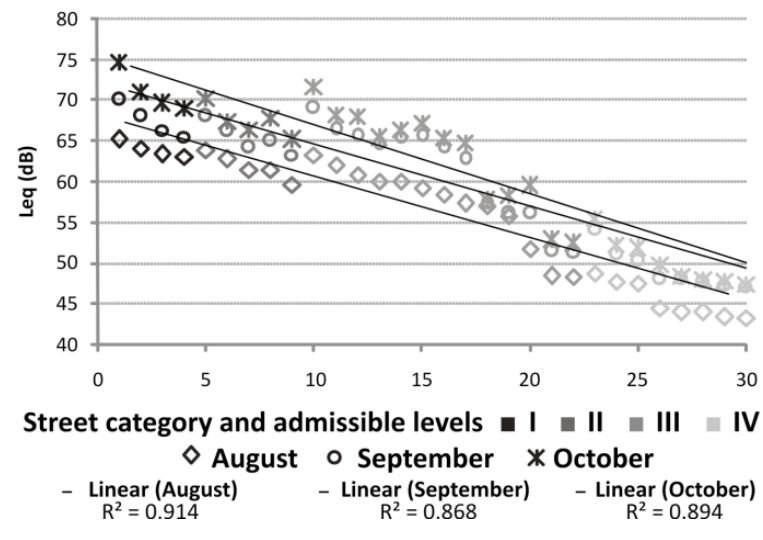

Fig. 2. Mean Leq values for each month and street category 
Tab. 1. Mean values for 30 monitored points by street category and seasons.

\begin{tabular}{|c|c|c|c|c|c|c|c|c|c|c|c|}
\hline $\begin{array}{c}\text { Street } \\
\text { category }\end{array}$ & $\begin{array}{c}\text { Point } \\
\text { number }\end{array}$ & Aug. & Sept. & Oct. & $\begin{array}{l}\text { Limit } \\
\text { values }\end{array}$ & $\begin{array}{c}\text { Street } \\
\text { category }\end{array}$ & $\begin{array}{c}\text { Point } \\
\text { number }\end{array}$ & Aug. & Sept. & Oct. & $\begin{array}{c}\text { Limit } \\
\text { values }\end{array}$ \\
\hline \multirow{5}{*}{ I } & 1 & 65.1 & 70.1 & 74.5 & \multirow{5}{*}{75} & \multirow{10}{*}{ III } & 11 & 59.9 & 65.5 & 66.3 & \multirow{10}{*}{65} \\
\hline & 3 & 63.9 & 68.0 & 70.9 & & & 6 & 51.7 & 56.0 & 59.5 & \\
\hline & 2 & 63.3 & 66.3 & 69.6 & & & 13 & 59.2 & 65.5 & 67.1 & \\
\hline & 4 & 63.0 & 65.5 & 68.9 & & & 17 & 58.4 & 64.2 & 65.2 & \\
\hline & 25 & 63.8 & 67.9 & 70.1 & & & 10 & 57.2 & 62.7 & 64.6 & \\
\hline \multirow{5}{*}{ II } & 28 & 62.7 & 66.2 & 67.2 & \multirow{5}{*}{70} & & 18 & 56.9 & 57.3 & 57.8 & \\
\hline & 27 & 61.4 & 64.2 & 66.2 & & & 5 & 55.8 & 56.1 & 58.1 & \\
\hline & 26 & 61.4 & 65.0 & 67.6 & & & 6 & 51.7 & 56.0 & 59.5 & \\
\hline & 29 & 59.6 & 63.2 & 65.1 & & & 8 & 48.4 & 51.4 & 52.8 & \\
\hline & 22 & 63.2 & 69.0 & 71.5 & & & 30 & 48.2 & 51.4 & 52.4 & \\
\hline \multirow{9}{*}{ III } & 19 & 62.0 & 66.3 & 68.1 & \multirow{9}{*}{65} & \multirow{9}{*}{ IV } & 23 & 48.7 & 54.2 & 55.4 & \multirow{9}{*}{60} \\
\hline & 21 & 60.8 & 65.5 & 67.8 & & & 7 & 47.6 & 51.0 & 52.1 & \\
\hline & 20 & 60.0 & 64.5 & 65.3 & & & 24 & 47.5 & 50.2 & 51.8 & \\
\hline & 11 & 59.9 & 65.5 & 66.3 & & & 16 & 44.4 & 48.0 & 49.7 & \\
\hline & 13 & 59.2 & 65.5 & 67.1 & & & 14 & 43.9 & 48.1 & 48.2 & \\
\hline & 17 & 58.4 & 64.2 & 65.2 & & & 9 & 43.9 & 47.6 & 47.8 & \\
\hline & 10 & 57.2 & 62.7 & 64.6 & & & 12 & 43.3 & 47.3 & 47.6 & \\
\hline & 18 & 56.9 & 57.3 & 57.8 & & & 15 & 43.2 & 47.1 & 47.3 & \\
\hline & 5 & 55.8 & 56.1 & 58.1 & & & & & & & \\
\hline
\end{tabular}

and October, because all scholar and economical activities were restarted.

Fig. 4. gives a profile of variation for a week for each month comparing Independetei bldv from first technical category with S. Barnutiu str., included in fourth category.

For the first one, the profile show that higher values are registered in third hour interval (13:30 - 14:30), mid-day when car, public transport and population fluxes are higher, the interval being well-known as rush-hour, followed by the first hour interval (7:00 - 8:00), when main activities start, with lower values in the remained three hours interval, with downward trend after the peak from mid-day the admissible level (75-85 $\mathrm{dB}$ ) were exceed in October only during the week, because in week-end the noise levels are lower.

The second one, S. Barnutiu str. noise profile reveal almost the same profile as Independetei Blvd., but with lower values, fit into over admissible level $(60 \mathrm{~dB})$, with insignificant differences (less than $5 \mathrm{~dB}$ ) between Monday to Friday and weekend, because an important memorial house (Ion Creanga's house) is situated in the area, the low width of the street and the lack of parking places represent major factors for low and constant values.

Comparing the two profiles, it was revealed also an higher amplitude of noise levels during the seasons on S. Barnutiu str., and lower amplitude on Independence Bldv. during Monday to Friday, and higher in weekend, due to higher values registered in all seasons.

Tab. 2 gives the Pearson correlation coefficients and their relationship between street category and sound level. As it can be observed, all the coefficients has a strong negative correlation, the results of the correlation confirm that there is a decrease in noise level with increasing street category.

Another statistical method used for study the similarities and differences between the street categories was Tukey-type test the results being presented in tab. 3. This is an important analysis that confirms the stratification of the noise on street, so that the categorization of streets according to their technical characteristics and use in communicating the different zones of a town was very relevant in studying urban noise. 
a.

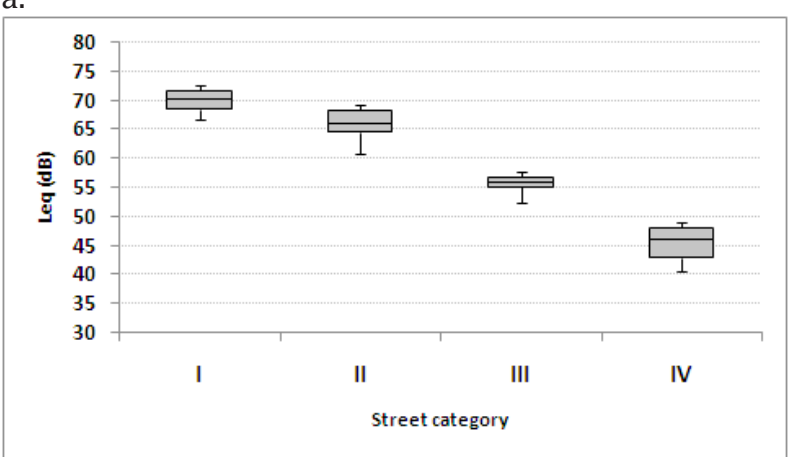

b.

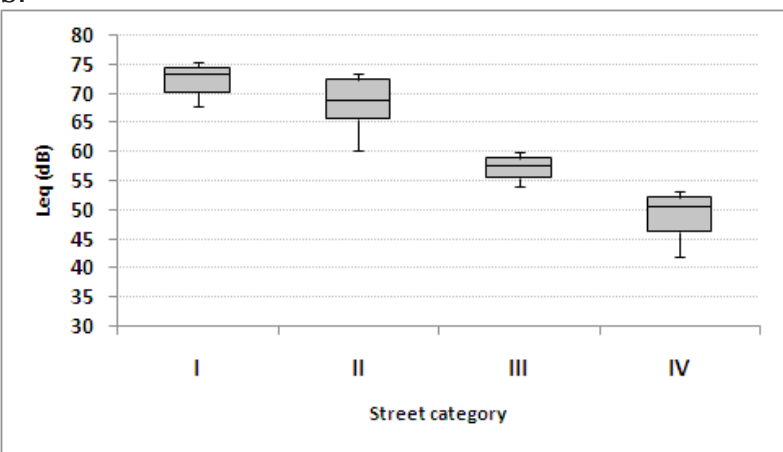

C.

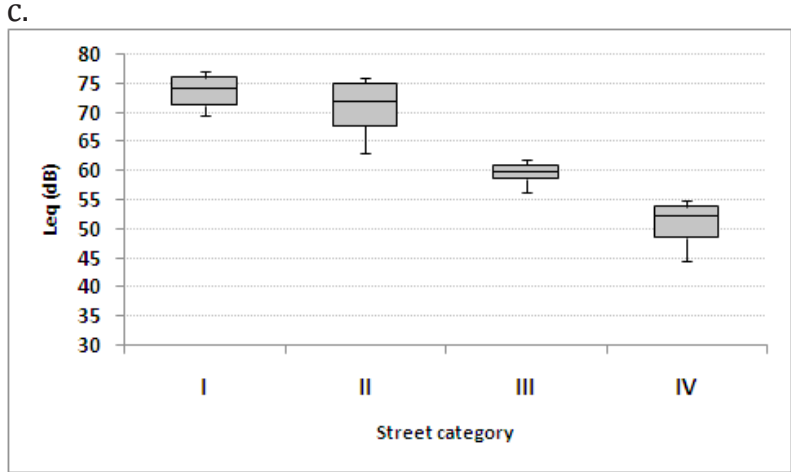

d.

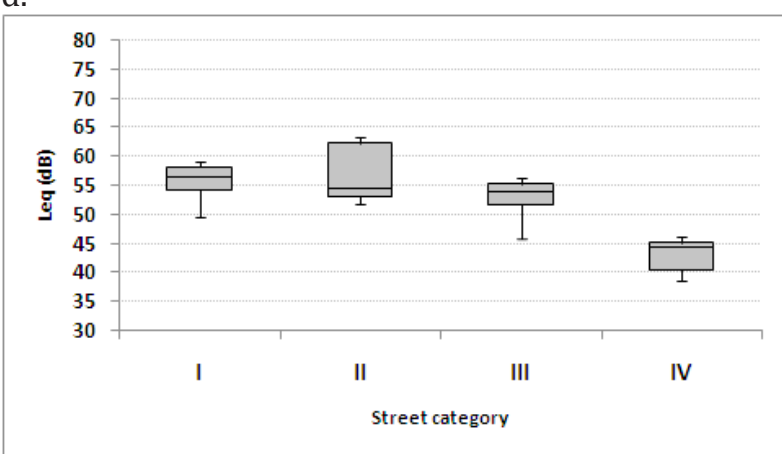

e.
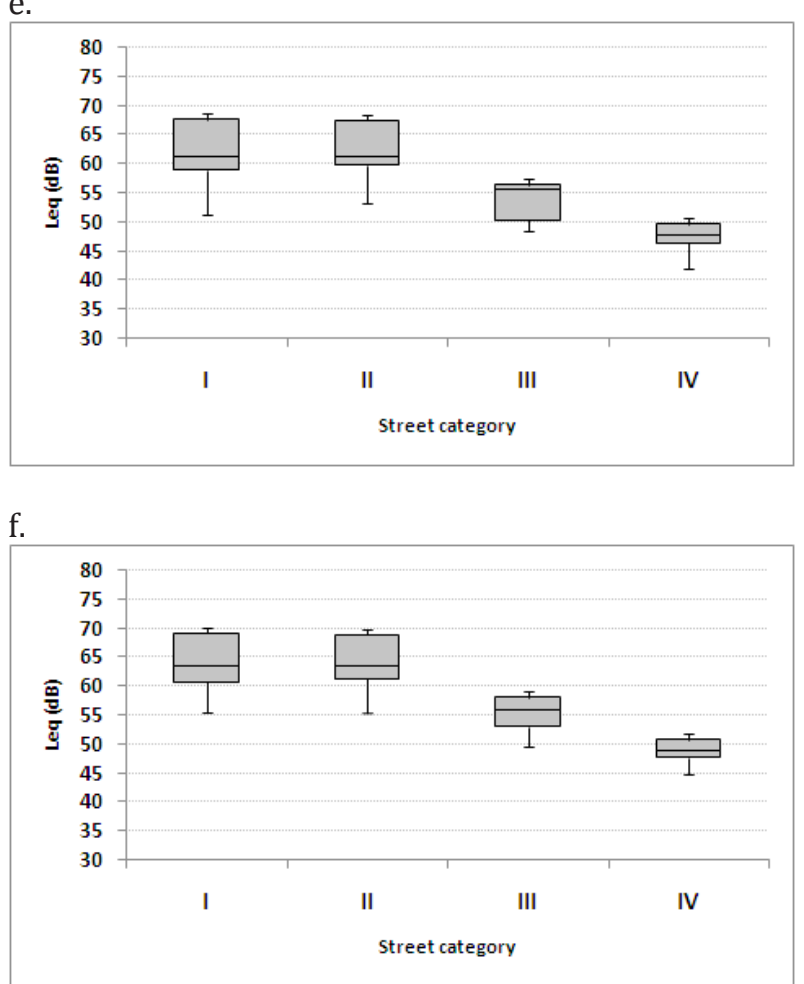

Fig. 3. Box-and-whisker diagram during the week, by categories for the different season : a. Monday to Friday - August, b. Monday to Friday - September, c. Monday to Friday - October, d. Weekend - August, e. Weekend - September, f. Weekend - October

The test reveal that the lower differences between first and second street category in monitored area due to heavy traffic supported by $\mathrm{C}$. A. Rosseti Blvd., that being in the same time one of the way out of town and ensuring the linking with east border and Sculeni customs. In opposition the Independetei Blvd. traffic was monitored and the best measures for traffic control were applied: installing traffic lights with timer at main road intersections, visible road signs, one-way road that are connected with main boulevard alternatively to reduce car flux and creation of bus-lane to improve public transportation system.

\section{Seasonal variation}

Seasonal variation is also revealed by the differences between seasons due to the main activities developed at monitoring time in the studied area.

Figure 5 gives the differences between in August - September from 0.3 to $6.3 \mathrm{~dB}$ and August - October from 0.8 to $9.4 \mathrm{~dB}$, with lower values on points located nearby the forest area and highest values in the nosiest point located at the largest road intersection from whole area, that connect four roads, included in different street type category in addition of bus-lane. 


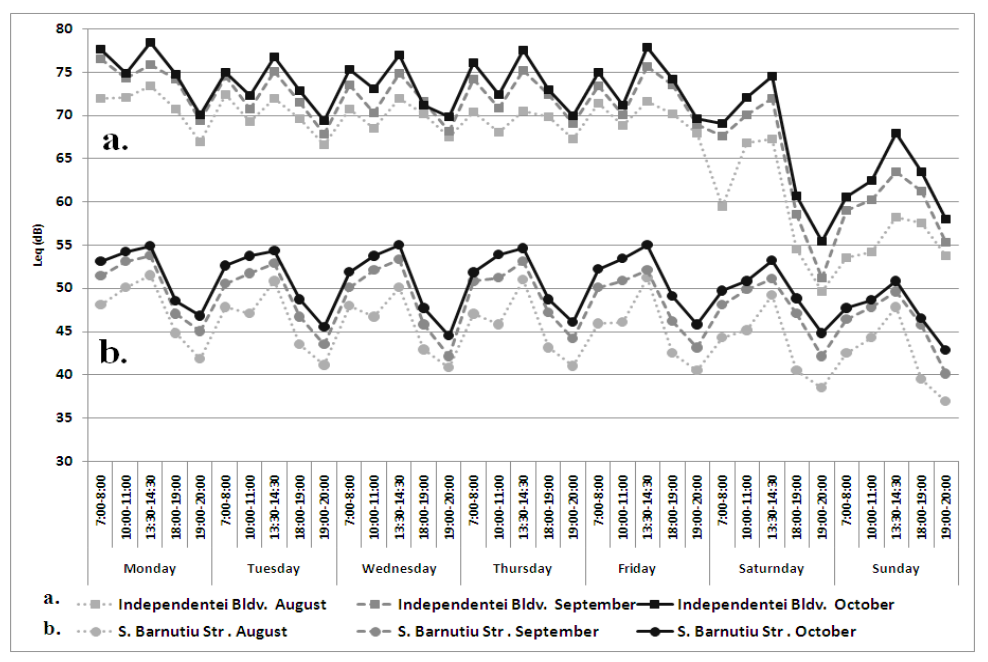

Fig. 4. Variation during the week between street a. category I (Independetei Bldv), b. category IV (S. Barnutiu str.)

Tab. 2. Pearson correlations coefficient between street categories and Leq $(\mathrm{dB})$

\begin{tabular}{ccc}
\hline Month & $\mathrm{N}$ & $\begin{array}{c}\text { Pearson correlation } \\
\text { coefficient }\end{array}$ \\
\hline August & 420 & -0.979 \\
\hline September & 420 & -0.968 \\
\hline October & 420 & -0.964 \\
\hline
\end{tabular}

This situation was caused by the low number of buses in August correlated with population present in the area and warm weather that permitted the walking in opposition with October when an important number of students came in city and the scholars that use public transport or personal cars because of cold weather.

Although the admissible levels weren't significantly exceeded on first and fourth street category, only on Sararie str., included in third category due to lack of public transport system in the area that encourage the car use and the larger number of public institution of sanitation and education and the proximity with Copou district were an important university of the city is located.

A comporarison with other studies is impossible, because is difficult to find a similar study in Romania, in other city, similar as population, size and street lane configuration in order to reveal significant similarities and differences, but mean values are similar for same type of city (Cluj city)
Tab. 3. Results of the Tukey test applied to the different categories of the five towns studied. Boldface values are below the critical value of the test

\begin{tabular}{ccc}
\hline $\begin{array}{c}\text { Compared } \\
\text { categories }\end{array}$ & $\begin{array}{c}\text { Tukey q - } \\
\text { statistics }\end{array}$ & $\begin{array}{c}\text { Critical } \\
\text { value }\end{array}$ \\
\hline $1-2$ & $\mathbf{2 . 0 4}$ & \\
\hline $1-3$ & 8.09 & \\
\hline $1-4$ & 24.93 & \multirow{3}{*}{3.99} \\
\hline $2-3$ & 6.19 \\
\hline $2-4$ & 24.28 \\
\hline $3-4$ & 29.81 & \\
\hline
\end{tabular}

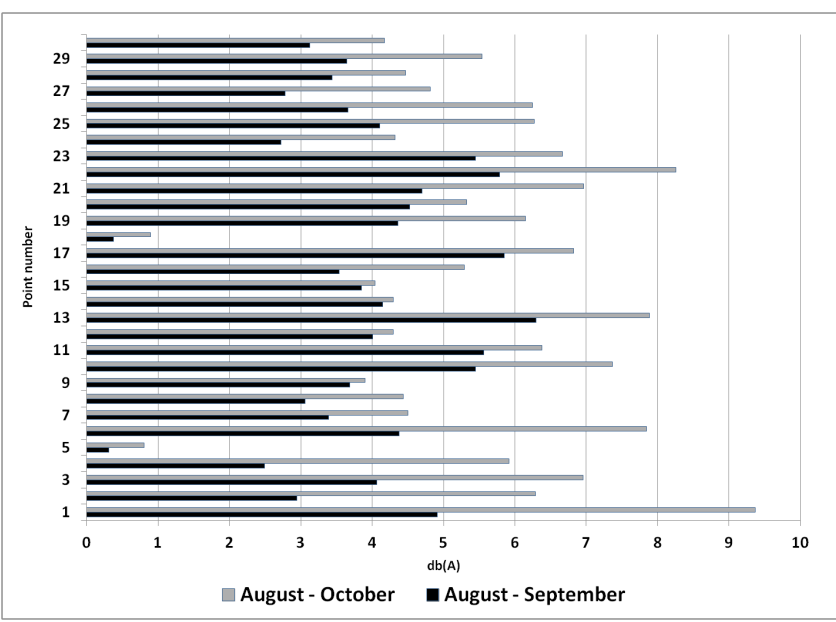

Fig. 5. Noise levels differences between seasons. 


\section{CONCLUSION}

The analysis of the noise levels and the seasonal transition variation highlight the following relevant aspects:

-Regarding the overtake of the admissible levels, mean values reveal overtakes for first street technical category in September and October and at only a point on second category street being recorded.

-The seasonal variations indicates differences between all months - lower values on August and higher in October, due to the variation of the social activities developed in the area: low number of inhabitants because of the holidays time in August and the resumption of the educational activity in autumn, including school start in September (differences from 0.3 to $6.3 \mathrm{~dB}$ ) and of the university activity in October (differences from 0.8 to $9.4 \mathrm{~dB}$ ).

-The variation during the week highlight differences between Monday to Friday and week-end, by the same pattern with high values in the morning and downward trends after midday rush-hour and in weekend with significant differences between street category, regarding also the amplitude of the values.

-A comporaison with other studies is difficult to realize.

\section{REFERENCES}

1. Al-Mutairi NZ, Al-Attar A, Al-Rukaibi S (2011). Trafficgenerated noise pollution: exposure of road users and populations in Metropolitan Kuwait, Environ Monit Assess 183:65-75

2. Babisch W (2005). Noise and health. Environ. Health Perspect. Guest editorial.113:A14-A15

3. Bluhm G, Nordling E, Berglind N (2004). Road traffic noise and annoyance - an increasing environmental health problem, Noise and health, A bimonthly Inter-disciplinary International Journal 6(24):43-49.

4. Can A, Leclercq L, Lelong J, Defrance J (2008). Capturing urban traffic noise dynamics through relevant descriptors, Applied Acoustics 69:1270-1280

5. Condorachi D (2002). Cateva aspecte privind abordare geografica a poluarii fonice, Lucrările Seminarului Geografic D.Cantemir $21-22$

6. Condorachi D (2006). Noise pollution mapping. EU timelines, indicators and methods of calculation, Lucrările Seminarului Geografic D.Cantemir 27.
7. Condorachi D (2009). Urban noise mapping in Romania. Preliminary results for Iasi city, Proceedings of NAG/DAGA 2009 International Conference on Acoustics, Rotterdam, The Netherlands 1401-1404.

8. Deliu M, Deliu Ghe (2008). Urban road traffic noise mapping, RECENT 9(324):39 - 44.

9. Demian G, Demian M, Grecu L, Grecu V (2009). Studies about Noise Pollution in Urban Areas, Proceedings of the $10^{\text {th }}$ WSEAS International Conference on Acoustics \& Music: Theory \& Applications: 87 - 91.

10. Herişanu N, Bacria V, Toader M, Popa Radovan S (2006). Investigation and Reduction of Ambient Noise in an Urban Area, Proceedings of the $7^{\text {th }}$ WSEAS International Conference on Acoustics \& Music: Theory \& Applications, 48-53.

11. Kihlman T (2006). Sustainable development in an urbanizing world-the noise issue. Noise News Int. 14:14-19.

12. Klaeboe R, Kolbenstvedt M, Fyhri A, Solberg S (2005). The impact of an adverse soundscape on road traffic noise annoyance. Acta Acustica united with Acustica, 91:10391050

13. Mihăiescu T, Odagiu A (2007). Noise pollution in urban areas. Case study - Cluj-napoca town, Bulletin USAMV-CN, 63:448-452.

14. Ohrstrom E, Skanberg A (2004). Annoyance and activity disturbances caused by road traffic noise-field studies on the influence of access to quietness. In: Proceedings of the $33^{\text {rd }}$ International Congress and Exposition on Noise Control Engineering, Prag, Czech Republic

15. Popescu DI, Tuns RE, Moholea IF (2011). The urban acoustic environment - a survey for road traffic noise, Carpathian Journal of Earth and Environmental Sciences, 6(1):285-292.

16. Surya A, Susham B, IIT K, Ghanshyam Y, (2010). Traffic Noise Mapping

17. Țârulescu S, Şoica AO, Țârulescu R(2007). Measurement of traffic noise pollution in urban areas, Annals of the Oradea University, Fascicle of Management and Technological Engineering 6(16): 602-609.

18. *** The Environmental Noise Directive (2002/49/EC)

19. *** http://ec.europa.eu/environment/noise/directive. htm

20. *** GD no 674/2007, Evaluation and Management of Environmental noise.

21. ***http://lege5.ro/Gratuit/geydmmrvgm/hotarareanr-674-2007-pentru-modificarea-si-completareahotararii-guvernului-nr-321-2005-privind-evaluarea-sigestionarea-zgomotului-ambiental 